\title{
The Distributional Effects of International
} Fragmentation

by

\section{Wilhelm Kohler ${ }^{*}$}

Working Paper No. 0201

April 2002

Johannes Kepler University of Linz Department of Economics Altenberger Strasse 69 A-4040 Linz - Auhof, Austria

${ }^{*}$ corresponding author: wilhelm.kohler@jku.at phone $+43(0) 702468-8239$ 


\title{
The Distributional Effects of International Fragmentation
}

\author{
by \\ Wilhelm Kohler (\#) \\ Department of Economics \\ Johannes Kepler University Linz
}

April 2002

\begin{abstract}
Economic globalization causes an increasing international fragmentation (disintegration) of value-added-chains, whereby firms outsource components of production to foreign markets. There is a high level of concern about unwelcome distributional effects. This paper provides a theoretical treatment of this issue within a general Heckscher-Ohlin framework, allowing for an arbitrary number of goods, factors, and fragments. It shows how a fragmented production equilibrium is disturbed by lower costs of fragmentation, and it introduces the concept of effective prices of fragments to derive general results that characterize the distributional consequences of an increase in international fragmentation occurring simultaneously in several industries.
\end{abstract}

JEL Code: D33, F11, F15, F23

Address: Altenberger Strasse 69, A-4040 LINZ-AUHOF

Phone: 0043-732-2468-8239, FAX: - 8238, E-mail: wilhelm.kohler@jku.at

Web: http://www.economics.uni-linz.ac.at/members/kohler

(\#): This work has been conducted under a research grant by the Austrian Science Fund: "Public Finance, Unemployment and Growth", grant no. P14702.

It builds on my EPRU Woking Paper 2001-03 entitled "International Fragmentation of Value-added-Chains: How Does it Affect Domestic Factor Prices". I am grateful to Michael Pflüger for helpful comments on the earlier version. 


\section{Introduction}

Industrial production is a multi-stage process. Some stages are carried out in an integrated way within firms, while others are outsourced to the market. In a market economy, the borderline between vertical integration and outsourcing is determined by profit maximizing firms who weigh the costs and benefits of governing production in an integrated, as opposed to disintegrated, way. This borderline is subject to change if the conditions that determine these costs and benefits change. Such changes are most likely to meet the public eye, and cause policy concern, if domestic firms are outsourcing parts of their value-added-chain to foreign economies and if the driving force is lower cost due to factor price differences, say cheaper foreign labor. We have seen several prominent examples of this happening in recent times, and a large body of systematic empirical research has documented that such international outsourcing is a significant and distinctive feature of the present wave of economic globalization. The international economy seems to have been undergoing a fundamental change, whereby production of individual goods is increasingly disintegrated, or fragmented, between countries with vastly different economic conditions. ${ }^{1}$

Sometimes, particularly in empirical research, international outsourcing is identified with trade in intermediates. In my view, however, the phenomenon of interest is not so much trade in intermediate goods as such, which is by no means new, although perhaps increasing in importance. International fragmentation involves a more fundamental process which questions the notion of a clear and watertight distinction between valueadded and intermediate goods at each stage of production. The process is perhaps best described as one where the principle of international arbitrage cuts into ever smaller slices of what were so far perceived as coherent elements of the value-added-chain. This is bound to aggravate the sense of vulnerability through open markets that often characterizes policy attitudes towards economic globalization.

From a theoretical perspective, international fragmentation involves two distinct challenges. ${ }^{2}$ One is to analyze the forces at work when firms decide whether to disin-

\footnotetext{
${ }^{1}$ An early characterization of this change can be found in Jones \& Kierzkowski (1990) who have pointed out that technological advances in certain types of services that are required to link different stages of production are an important driving element. For similar, more recent accounts, see Harris (1995,2001), and Jones \& Kierzkowski (2001a). For empirical studies, see Irwin (1996), Feenstra (1998), Hummels et al. (1998, 2001), and several papers in Arndt \& Kierzkowski (eds., 2001).

${ }^{2}$ Throughout this paper, I use the terms international outsourcing, international fragmentation,
} 
tegrate production. This leads right into the theory of the firm, which tries to explain why in some cases production takes place in a vertically integrated way, relying on intra-firm hierarchies, while in others it relies on market transactions. Basically, the relevant decision problem has two dimensions: one is whether to disintegrate at all, and the other is whether or not to do so across national borders. Thus, Grossman \& Helpman (2002a) develop a general equilibrium model focusing on the costs and benefits of outsourcing in a closed economy environment, while in Grossman and Helpman (2002b) outsourcing as such is an exogenous necessity and the question is whether it will be done across national borders. ${ }^{3}$ At any point in time, the relevant conditions may change in such a way that there is a tendency of increasing integration on the firm level, with a simultaneous tendency of international disintegration. The result then is an emergence of vertical multinational firms, as for instance described in Markusen (2001 and 2002).

The second challenge is to explore the general equilibrium consequences of such an increase in international fragmentation if, for whatever reason, it occurs. As noted by Jones \& Kierzkowski (1990 and 2001a), one might generally expect that international fragmentation increases the scope for gains from trade. ${ }^{4}$ But we know that such gains rarely come without pains, particularly in the form of unwelcome distributional effects. It is thus not surprising that in the second half of the 1990s outsourcing was taken up on a somewhat less optimistic tone. Specifically, starting with Krugman (1995), outsourcing has been debated as a possible culprit in connection with the concern that has meanwhile arisen about the distributional consequences of economic globalization.

In principle, the second challenge is not independent from the first, since the consequences of outsourcing will presumably be an important ingredient in explaining the extent to which it happens. However, models attempting to describe the forces behind international fragmentation will often be quite stylized in precisely those aspects relevant for income distribution. For instance, Grossman \& Helpman (2002b), while employing a general equilibrium model, assume a single factor (labor) which rules out distributional issues. Conversely, models highlighting distributional consequences are typically quite stylized when it comes to the driving forces of outsourcing. This is true also for the present paper. In order to sharpen the focus on distributional effects of

and international disintegration synonymously.

${ }^{3}$ See also McLaren (2000).

${ }^{4}$ See also a related recent paper by Samuelson (2001). 
an increase in international fragmentation, the cause of this increase is modeled in an easy, and relatively rudimentary, way. ${ }^{5}$

Previous analyses have produced a vast array of different results that sometimes seem contradictory and are in general difficult to understand as manifestations of a single principle. In their seminal papers, Feenstra \& Hanson (1996 and 1997) argue, both theoretically and empirically, that outsourcing in connection with US-foreign direct investment in Mexican Maquiladoras explains why wages for unskilled labor have declined relative to skilled labor in both countries, while at the same time production has become more skill-intensive. Arndt (1997 and 1999) argues that under certain conditions US labor will gain from Maquiladora-type outsourcing to Mexico. He employs a $2 \times 2$ Heckscher-Ohlin-type model with labor and capital, but his argument may easily be re-framed using skilled and unskilled labor instead, in which case his result is in stark contrast to that of Feenstra and Hanson. ${ }^{6}$ Venables (1999) demonstrates that even in a single two-sector model several different outcomes may arise, including "some curious cases". Using a somewhat more general framework, Jones \& Kierzkowski (2001a and 2001b) discuss a host of different outcomes - "some rather surprising" - where fragmentation may be beneficial or harmful to low-skilled workers in relation to skilled workers or capital, depending on a complex interplay between the factor endowment position and output pattern of a country on the one hand, and the details of the fragmented activities on the other. The richness of possible results is further demonstrated in the work of Deardorff (2001a and 2001b) who focuses on international factor price equalization, rather than domestic income distribution. In Deardorff (2001a), he shows that fragmentation increases the likelihood of international factor price equalization in that it renders factor price equalization an equilibrium outcome for certain factor endowments which would otherwise rule this out. However, in Deardorff (2001b) he warns against reading too much into this result, pointing out that under certain conditions fragmentation may actually increase international factor price differences.

\footnotetext{
${ }^{5}$ While some trade-off of this kind is unavoidable, it is often important for models focusing on the welfare and distributional consequences to specify what type of cost is involved. For instance, in Kohler (2001) I show that it matters a lot for welfare consequences whether or not there is a fixed cost of outsourcing. In this paper, I assume that there is no fixed cost element involved.

${ }^{6}$ In Kohler (2001), I have shown that this difference is best understood in terms of the difference between factor-biased technological change and sector-biased technological change, in connection with the question of whether technological change happens in a closed or in an open economy; see also Krugman (1995).
} 
In some sense, it is not surprising that a phenomenon as generic as fragmentation should be associated with a variety of different possible factor price changes. But at the same time, it is surely not true that anything can happen. While the casuistic discussion of the existing literature does shed light on the issue, we are still missing is a concise formulation of a general principle which is at force in each special case. This paper suggests a general equilibrium framework of analysis which allows us to formulate such a principle. The framework addresses the distributional consequences of international fragmentation in a world where trade is determined by a coexistence of Ricardian and Heckscher-Ohlin-type comparative advantage. An important element of the analysis is that it allows for an arbitrary number of goods, factors and value-added components (fragments). It assumes that outsourcing takes place from a domestic economy to a neighboring country both of which face given world prices for final goods. Factor price differences between these countries form the key incentive to carry out international fragmentation. The analysis assumes a constant returns to scale technology and perfect competition.

The paper is structured as follows. Section 2 presents an informal account of the analysis and its core results. Section 3 introduces a formal description of a technology that allows for fragmentation of production. It then describes a trading equilibrium, first for the case where production in each industry is vertically integrated within the domestic economy, and then for a case where value-added in each industry is fragmented across national borders. This involves the definition of effective prices for fragments of value-added, and it gives rise to the notion of a "margin of international disintegration". Section 4 shows that a shift in this "margin" involves a Stolper-Samuelson-type disturbance, and it explains the magnitude of this disturbance in terms of relevant industry characteristics. Section 5 then allows such disturbances to arise simultaneously in several industries, exploring the general equilibrium implications for factor prices. It identifies conditions under which some factors will necessarily lose from outsourcing, and it derives a key proposition describing how the distributional consequences from international fragmentation depend on the industry-pattern of outsourcing. This proposition is then used to reconstruct special cases that have been discussed in the previous literature. Section 6 concludes the paper with suggestions for further research.

\section{An informal account}

In trade theory, a defining element of a production process is that it is carried out under a single set of factor prices, domestic or foreign. The distinctive feature of international, 
as opposed to domestic, outsourcing is that it allows production of a single good, or a single value-added-process, to draw on different factor markets with differing factor prices. Domestic outsourcing is, almost by definition, outsourcing to a market with the same factor prices. In contrast, international outsourcing, as defined in this paper, responds to factor price differences in trying to achieve cost-savings through a suitable match between the production characteristics of individual fragments of value-added and the pattern of factor prices prevailing in foreign countries. If technology permits production to be fragmented, then un-exploited cost-savings of this kind, duly taking into account all costs of disintegrating production cross-borders, are inconsistent with equilibrium. And any existing equilibrium will be disturbed if such opportunities arise due to lower costs of disintegrated production.

As long as production is integrated within firms, individual fragments (or components) of the value-added process do not carry market prices. ${ }^{7}$ However, one may impute a value to any one fragment of such a process which is equal to the market price of the final good less the cost incurred for all other components, as required per unit of the final good. In reference to the effective protection literature we may call this the "effective price" of a fragment; see Ethier (1977). The equilibrium condition of zero profits implies that the opportunity cost of the resources used to produce any fragment are equal to its effective price. Conversely, if the opportunity cost of procuring a value-added-fragment from foreign factor markets falls below its present effective price, say because of lower costs of fragmented (as opposed to integrated) production, then the equilibrium is disturbed by an incentive to pursue international fragmentation, or outsourcing. By lowering the cost of the fragments that are outsourced to foreign factor markets, such international fragmentation raises the effective price of those fragments which remain in the domestic value-added-chain. This is the general principle behind all results obtained in this paper. The approach contrasts with the previous literature in that it maps international outsourcing into equivalent price changes, rather than equivalent technology changes; see Feenstra \& Hanson (1999).

If production allows for fragmentation, then the aggregate factor bundle used for certain good can be thought of as a composite of several factor bundles representing individual fragments. International fragmentation means that firms draw on foreign factor markets for some of these fragments. The first result (Theorem 1) is a characterization of an equilibrium fragmented production pattern by means of a hyperplane in

\footnotetext{
${ }^{7}$ Throughout the analysis, I use the terms fragment and component synonymously.
} 
factor space which separates fragments that are outsourced to the foreign country from those produced domestically. The position of this plane is determined by Ricardian differences in technology, by factor price differences prevailing between the two countries, and of course by the costs of international fragmentation. In general equilibrium, there is one such hyperplane for each final good produced. I will call these hyperplanes "margins of disintegration". For analytical purposes, scenarios of globalization that involve technological advances as well as reductions in trading and communication costs can usefully be described as changing the position of these hyperplanes, causing a disturbance of the initial equilibrium, and a subsequent adjustment whereby an increasing number of fragments change their location of production and, perhaps more importantly, which involves a change in domestic factor prices.

The second result of the paper (Theorem 2) looks more closely at the disturbance of the zero profit condition that emerges in any one industry if some globalization scenario displaces its margin of disintegration. It determines the magnitude of this disturbance from the specific characteristics of the marginal fragment affected by this shift, in conjunction with the Ricardian technology gaps and the factor-price differences prevailing in the initial equilibrium. Intuitively, the cost-savings achieved from outsourcing a particular fragment of value-added in a certain industry constitute a gain that "mandates" paying higher rewards to the factors that contribute to the residual domestic fragments of that industry's value-added-chain. Theorem 3 identifies conditions under which this industry-gain may be seen as a Stolper-Samuelson disturbance in the sense of an equivalent increase in the effective price of that particular industry's residual domestic product.

The factor price effect following from such a disturbance cannot be determined by looking at one industry in isolation. Different industries typically draw on common pools of primary factors, hence factor price effects can only be determined by a full general equilibrium analysis. This requires broadening the perspective to all industries and including factor market equilibrium, in addition to the zero-profit equilibrium conditions. Intuitively, the different factors will not benefit proportionally from the above mentioned industry-gain. Indeed, as shown in Theorem 4, although in the case considered in this paper the country as a whole always gains from outsourcing, under certain conditions at least one factor must suffer a real income loss. However, this is an extreme case of an income distribution effect of international fragmentation, and the result is of little help as it does not tell us which factor loses. Theorem 5 therefore introduces a measure for distributional effects which is more appropriate for the present case, and it shows that the distributional consequences of international fragmentation 
are not at all determined by the factor-intensity pattern of those fragments which are outsourced to the foreign economy. Instead, they are determined by the factor intensity of the activities that remain economically viable in the domestic economy and which have increased in value according to Theorem 3. Which of the activities remains viable domestically is, in turn, determined by the intersectoral pattern of the Stolper-Samuelson disturbances that arise in the process of outsourcing.

If Theorem 5 is the general principle called for in the introduction above, then it should be possible to reconstruct various cases discussed in the existing literature as special instances arising under specific conditions. This can, indeed, be done as shown by two Corollaries to Theorem 5 .

\section{Equilibrium under fragmentation}

\subsection{Technology}

Suppose there are $I$ traded goods, produced with $M$ primary factors according to a constant returns to scale technology. Assuming that there is perfect competition on domestic factor markets, we may describe the technology by means of concave unit-cost functions $c_{i}(w)$, where $w$ is a vector of domestic factor prices. Fragmentation implies some form of separability in production functions, which must be reflected in the unitcost functions. I model this in a relatively easy and straightforward manner, such that the for the domestic economy unit cost functions may be written as

$$
c_{i}(w)=f_{i}\left[c_{i}^{1}(w), c_{i}^{2}(w), \ldots c_{i}^{F}(w)\right] .
$$

I thus assume a given number of fragments (components) which, for simplicity, is equal to $F$ for all goods. Each component has an associated minimum unit-cost function $c_{i}^{f}(w)$. This suggests that fragments have "natural" units. We shall return to this question below. Notice that this is quite a strong form of separability, implying that the unit factor demands for each fragment depends only on factor prices at its location of production, and is independent on how, and where, other fragments are produced. This is obviously important in the context of outsourcing. Moreover, the above technology assumes that all fragments are essential. Using $\nabla c_{i}(w)$ to denote the gradient of the unit-cost function, the vector of cost-minimizing input requirements per unit-value of 
final output produced in the domestic economy is

$$
\begin{aligned}
a_{i}(w) & =\nabla c_{i}(w) / p_{i} \\
& =\frac{1}{p_{i}} \times\left[\frac{\partial f_{i}}{\partial c_{i}^{A}} \nabla c_{i}^{1}(w)+\frac{\partial f_{i}}{\partial c_{i}^{B}} \nabla c_{i}^{2}(w)+\ldots+\frac{\partial f_{i}}{\partial c_{i}^{B}} \nabla c_{i}^{F}(w)\right] \\
& =a_{i}^{1}(w)+a_{i}^{2}(w)+\ldots+a_{i}^{F}(w),
\end{aligned}
$$

where $p_{i}$ is the price of final good $i$ which we assume to be given and constant throughout the analysis. Thus, $a_{i}^{f}(w)$ denotes the cost-minimizing input bundle used in fragment $f$ of the value-added-chain per unit-value of the final good $i$.

The foreign economy has the same technology, except for Ricardian differences in productivity. Both countries face the same commodity prices, but they have different factor prices, due to factor endowment differences and/or trade barriers. We need not model this in detail. If $w^{*}$ denotes foreign factor prices, the cost-minimizing input requirements per unit-value of final outputs produced abroad are

$$
\begin{aligned}
a_{i}^{f *}\left(w^{*}\right) & =\tau_{i} a_{i}^{f}\left(w^{*}\right), \quad f=1 \ldots F, \\
\text { and } \quad a_{i}^{*}\left(w^{*}\right) & =a_{i}^{1 *}\left(w^{*}\right)+a_{i}^{2 *}\left(w^{*}\right)+\ldots+a_{i}^{F *}\left(w^{*}\right) .
\end{aligned}
$$

If $\tau_{i}>1$, then the foreign country has a Ricardian productivity disadvantage in industry $i$, and vice versa. I assume that such differences are industry-specific, but not specific to individual fragments.

It is important to note that $a_{i}^{*}\left(w^{*}\right)$ and $a_{i}^{f *}\left(w^{*}\right)$ are cost-minimal inputs assuming that all production takes place under a single set of factor prices $w^{*}$, and similarly for $a_{i}^{*}\left(w^{*}\right)$ and $a_{i}^{f *}\left(w^{*}\right)$ with factor prices $w$. With international fragmentation, however, part of production takes place under factor prices $w$, while the rest takes place with prices $w^{*}$. Writing $\tilde{a}_{i}^{f}$ for input bundles per unit of fragment $f$, we have $a_{i}^{f *}\left(w^{*}\right)=$ $\tilde{a}_{i}^{f *}\left(w^{*}\right) q_{i}^{f}$, where $q_{i}^{f}$ measures the level of fragment $f$ employed in industry $i$ valueadded which will depend on the relative unit-cost of fragment $f$, and thus also on factor prices $w$. If technology on the (upper) level of fragments is of the Leontief-type, then $q_{i}^{f}$ is a constant (for a given price $p_{i}$ ).

\subsection{Equilibrium with integrated production}

As a point of reference, I first characterize an international equilibrium where all production is integrated within each country. A zero profit equilibrium satisfies the following two sets of inequalities:

$$
\begin{aligned}
1 & \leq w^{T} a_{i}(w) \leq w^{T}\left[a_{i}^{*}\left(w^{*}\right) / \tau_{i}\right] \\
\text { and } \quad 1 & \leq w^{* T} a_{i}^{*}\left(w^{*}\right) \leq w^{* T}\left[a_{i}(w) \tau_{i}\right]
\end{aligned}
$$


In both expressions, the first inequality simply states that the minimum cost of producing a unit-value of output must not be less than 1 in either country, given its factor prices. For goods produced domestically, the equality must obtain. The second inequality follows from cost-minimization. $a_{i}^{*}\left(w^{*}\right)$ is what cost minimizing foreign firms would do to generate a unit-value of output, when faced with factor prices $w^{*}$. Given the assumed Hicks-neutral difference in technology, the bundle $a_{i}^{*}\left(w^{*}\right) / \tau_{i}$ is a feasible way for domestic firms to generate a unit-value of output. Cost-minimization, therefore, implies the second inequality in 5. The interpretation of 6 is analogous.

We make no special assumption about the pattern of specialization. If there is a subset of goods $S$ which are produced domestically but not produced abroad, and a subset $S^{*}$ which is only produced by the foreign economy, then we must have ${ }^{8}$

$$
\begin{aligned}
\left(w-w^{*} \tau_{i}\right)^{T} a_{j}(w) & <0 \quad i \in S \\
\text { and } \quad\left(w^{*}-w / \tau_{i}\right)^{T} a_{j}^{*}\left(w^{*}\right) & <0 \quad i \in S^{*} .
\end{aligned}
$$

Figure 1 illustrates an equilibrium for the case for two factors, $\mathrm{K}$ and L, and 4 goods, labeled 1 through 4 . The line labeled $w^{*} \tau_{2}$ connects factor bundles satisfying $\tau_{2}\left(w_{K}^{*} K+w_{L}^{*} L\right)=1$, while the line $w$ depicts $\left(w_{K} K+w_{L} L\right)=1$. By construction, $\tau_{2}>1$, i.e., the foreign economy has a Ricardian disadvantage in good 2 . The position of line $w^{*} \tau_{2}$, relative to $w$, captures this disadvantage, and since the line is entirely below the unit-value isoquant for good 2 (labeled $1 / p_{2}$ ), while $w$ is tangent to the isoquant, good 2 is only produced domestically. Analogous interpretations hold for all 4 goods. Figure 1 thus depicts a case where good 1 is not produced domestically, while goods 2 and 3 are not produced abroad and good 3 is produced in common. To avoid clutter, only factor bundles $a_{2}(w)$ and $a_{4}^{*}\left(w^{*}\right)$ are depicted. Notice that, because of the Ricardian difference in technology, this pattern does not uniquely reflect the factor intensity ordering. ${ }^{9}$ For the same reason, we have non-equalized factor prices in overlapping cones of diversification.

\subsection{Equilibrium with disintegrated production}

The above equilibrium conditions are in terms of integrated technologies, assuming that there is no international fragmentation. Using the notion of effective prices, a similar

\footnotetext{
${ }^{8}$ All of these goods are, of course also produced in the rest of the world economy which we need not look at for our purpose.

${ }^{9}$ Technological differences here act much like tariffs on intermediates in Deardorff (1979).
} 
characterization of the equilibrium can now be obtained with respect to individual fragments, allowing for international fragmentation, i.e., disintegration of production. I define the effective price of fragments.

Definition 1 (effective price) For a zero-profit equilibrium where all production is integrated domestically, the effective price of any fragment $f$ in industry $i$ is defined as

$$
\pi_{i}^{f}=1-\sum_{g \neq f} w^{T} a_{i}^{g}(w), \text { with } g, f=1 \ldots F .
$$

In the more general case, where some fragment $g$ is already produced abroad, the term $w^{T} a_{i}^{g}(w)$ is replaced by the corresponding foreign factor cost $w^{* T} \tilde{a}_{i}^{g *}\left(w^{*}\right) q_{i}^{g}$.

The effective price $\pi_{i}^{f}$ is nothing but what is left over from a unit of revenue from final good $i$, after paying the minimum cost of securing all other fragments, given the factor prices prevailing at their respective locations of production. Notice that the definition relates to a specific equilibrium with associated input levels $q_{i}^{f}$ for individual fragments. Notice also that in the above definition $a_{i}^{g}(w)=\tilde{a}_{i}^{g}(w) q_{i}^{g}$. Thus, $\pi_{i}^{f} / q_{i}^{f}$ is an imputed market value for a unit of fragment $f$ in industry $i$, or a price "mandated" by the factor cost of securing all other fragments required quantities. ${ }^{10}$ Without loss of generality, we scale fragments such that in the initial equilibrium $q_{i}^{f}=1$ for all $f$ and $i$. Effective prices as defined above are functions of both final commodity prices and factor prices, including foreign factor prices if production is disintegrated to start with. However, since we assume given commodity prices, we shall henceforth only emphasize dependence on factor prices. ${ }^{11}$

We can now re-frame the zero-profit conditions in terms of effective prices. Specifically, looking at the case of integrated domestic production, the condition $1 \leq w^{T} a_{i}(w)$ implies

$$
\pi_{i}^{f}\left(w, w^{*}\right) \leq w^{T} a_{i}^{f}(w), \quad f=1 \ldots F
$$

which states that the minimum cost of fragment $f$ must be equal to its imputed effective price if produced domestically, or else exceed this price whence it will be outsourced; see below. There are $F$ inequalities of this kind, each of which - together with the

\footnotetext{
${ }^{10}$ Compare Leamer's (1998) notion of factor price changes "mandated" by goods price changes and technology changes.

${ }^{11}$ Compare the definition of effective prices in the theory of effective protection; see Ethier (1977).
} 
corresponding definition 9 - is an equivalent expression of the fundamental zero profit equilibrium condition, i.e., equivalent to the first inequality in 5 .

The case of disintegrated production is complicated by the fact that production takes place under two sets of factor prices, $w$ and $w^{*}$. However, the above mentioned assumption of separability in production makes things tractable. We only need to observe the distinction between input bundles per unit of a fragment, $\tilde{a}_{i}^{f}$, and input bundles used per unit-value of the final good, $a_{i}^{f}$. If fragment $f$ is produced at home, we have $a_{i}^{f}(w)=\tilde{a}_{i}^{f}(w) q_{i}^{f}$, where $q_{i}^{f}$ in general depends on both domestic and foreign factor prices; see above. Barring international fragmentation, $q_{i}^{f}$ is a function only of domestic factor prices, but with disintegrated production it becomes a function also of foreign factor prices. Although we have scaled fragments in such a way that the initial equilibrium features $q_{i}^{f}=1$ throughout, it is still important to observe the conceptual difference between $a_{i}^{f}(w)$ and $\tilde{a}_{i}^{f}(w)$.

In order to characterize an equilibrium with disintegrated production, we use our definition of effective prices, to envisage a unit-value level of fragment $f$ in industry $i$ corresponding to a disintegrated production equilibrium:

$$
b_{i}^{f}(w)=\tilde{a}_{i}^{f}(w) / \pi_{i}^{f}\left(w, w^{*}\right) .
$$

These are simply scaled-up versions of the factor bundles $\tilde{a}_{i}^{f}(w)$, such that $b_{i}^{f}(w)$ represents a value of one, given $\pi_{i}^{f}$. Moreover, we define

$$
b_{i}^{f *}\left(w^{*}\right)=\tilde{a}_{i}^{f *}\left(w^{*}\right) / \pi_{i}^{f}\left(w, w^{*}\right)
$$

which is the unit-value level of foreign production of fragment $f$, assuming that it, together with all other components, feeds into domestic assembly of the final good $i$, (hence the use of the domestic effective price on the right-hand side of 12). Notice the that 12 uses $\tilde{a}_{i}^{f *}(w)$, rather than $a_{i}^{f *}(w)$. It thus denotes the factor bundle employed by cost-minimizing firms in order to produce fragment $f$ in the amount actually employed per unit-value of good $i$ in the initial equilibrium which we now assume to feature disintegrated production, with some fragments produced under $w$ and others under $w^{*}$. In contrast, $a_{i}^{f *}(w)$ is the factor bundle used for that fragment if all production took place in an integrated way under factor prices $w^{*}$. Notice, once again, our definition of units implying that $q_{i}^{f}=1$, given factor prices $w$ and $w^{*}$ and the associated pattern of international fragmentation. We now proceed to characterize this pattern of fragmentation.

The domestic zero-profit condition 10 implies

$$
w^{T} b_{i}^{f}(w) \geq 1 .
$$


for all $i$ and $f$. In equilibrium, domestic minimum cost of a unit-value level of fragment $f$ in industry $i$ cannot be less than one, and it must be equal to one if this fragment is produced domestically. Invoking revealed cost-minimization, we arrive at the following condition:

$$
1 \leq w^{T} b_{i}^{f}(w) \leq w^{T}\left[b_{i}^{f *}\left(w^{*}\right) / \tau_{i}\right]
$$

This is similar to, yet also different from condition 5 above. As expected, the possibility to disintegrate production makes a difference. Figure 2 illustrates this by isolating good 3 from the earlier figure. Barring international fragmentation, the case depicted would be an equilibrium, where integrated production of good 3 is viable (non-viable) domestically (abroad). Formally, for $i=3$ condition 7 is satisfied, while 8 is not. But if disintegration becomes possible, this is no longer an equilibrium. More specifically, integrated production, while satisfying condition 14 , violates

$$
1 \leq w^{* T} b_{i}^{f *}(w)
$$

for $f=1$ and $i=3$. This is analogous to 6 , and it states that in equilibrium foreign production of fragment $f$ with domestic assembly of the final good must not yield a positive profit. If this condition is violated for any fragment $f$, then integrated production cannot be an equilibrium, and international fragmentation must prevail.

It is perhaps more intuitive to look at the domestic equilibrium conditions under fragmentation from a cost-savings perspective. Then, violation of condition 15 simply means that domestic firms can reduce the cost of generating a unit-value below one by outsourcing fragment $f$ to foreign production.

\subsection{The margin of disintegration}

This is a natural stage to introduce costs of international fragmentation. Jones \& Kierzkowski (1990 and 2001a) emphasize that such costs are a crucial element behind the recent upsurge of outsourcing. The specific form in which they arise plays an important role in various circumstances; see Harris (2001) and Kohler (2001). For the present purpose, I employ a simple ice-berg-type specification. Thus, if home firms produce fragment $f$ of good $i$ in the foreign country and then combine it with the domestic chain of value-added, they incur trading and communication cost in the advalorem amount of $\gamma_{i}-1>0 .{ }^{12}$ As with the Ricardian technology gaps, I assume that

\footnotetext{
${ }^{12}$ The term $a_{j}$ may in part also represent formal trade barriers like tariffs, but we shall henceforth assume that it represents real trading costs.
} 
these costs are uniform across fragments within an industry.

Generally, one expects that the difference in factor prices, as well as productivity differences and the costs of disintegration determine the extent to which international fragmentation takes place. This is substantiated in precise terms by the following theorem:

Theorem 1 (margin of disintegration) In an equilibrium where production may be disintegrated, $\left(w-\gamma_{i} \tau_{i} w^{*}\right)^{T} a=0$ defines a hyperplane in factor space which represents a margin of disintegration (fragmentation) for industry $i$ in the following sense:

1. Any fragment $g$ with a factor input bundle $b_{i}^{g *}\left(w^{*}\right)$ that satisfies $\left(w-\gamma_{i} \tau_{i} w^{*}\right)^{T} b_{i}^{g *}\left(w^{*}\right)<$ 0 is an integral part of the domestic value-added.

2. For any fragment $h$ which is disintegrated from the domestic value-added chain in industry $i$, the factor input bundle $b_{i}^{h}(w)$ must satisfy $\left(w-\gamma_{i} \tau_{i} w^{*}\right)^{T} b_{i}^{h}(w)>0$.

The proof is straightforward. Equilibrium requires that domestic firms cannot further reduce unit-cost by changing the location where individual fragments are produced. Per unit of fragment $f$ the savings from outsourcing may be written as

$$
s_{i}^{f}=w^{T} \tilde{a}_{i}^{f}(w)-\gamma_{i} w^{* T} \tilde{a}_{i}^{f *}\left(w^{*}\right)
$$

Taking statement 2 first, suppose some fragment $h$ were produced domestically, while $s_{i}^{h}>0$. This would imply that firms forego cost-savings even at unchanged levels of fragments $q_{i}^{h}=1$. If technology allows for substitution between fragments, these savings could even be increased by employing more of fragment $h$ once produced at lower cost abroad. Conversely, suppose that $s_{i}^{g}<0$ and fragment $g$ were outsourced. Then, by analogous reasoning, firms would forego cost-savings by relocating production of fragment $g$ to the home economy. Now, cost-minimization implies that for all fragments $f$

$$
\begin{aligned}
w^{T} \tilde{a}_{i}^{f}(w) & \leq w^{T} \tilde{a}_{i}^{f *}\left(w^{*}\right) / \tau_{i} \\
\text { and } \quad w^{* T} \tilde{a}_{i}^{f *}\left(w^{*}\right) & \leq w^{* T} \tau_{i} \tilde{a}_{i}^{f}(w) .
\end{aligned}
$$

Inequality 18 implies that $s_{i}^{f}>0$ if $\left(w-\gamma_{i} \tau_{i} w^{*}\right)^{T} \tilde{a}_{i}^{f}(w)>0$, and 17 implies that $s_{i}^{f}<0$ if $\left(w / \tau_{i}-\gamma_{i} w^{*}\right)^{T} \tilde{a}_{i}^{f *}\left(w^{*}\right)<0$. And given the definitions of $b_{i}^{f}(w)$ and $b_{i}^{f *}\left(w^{*}\right)$ in 11 and 12 above, this implies statements 1 and 2, respectively, of Theorem 1.

Figure 2 illustrates this theorem. If disintegration is possible only at a cost, so that $\gamma_{3}>1$, then the relevant hyperplane is $A$ and production remains integrated 
domestically. If it is costless, then $\gamma_{3}=1$ and the relevant hyperplane is $B$ in which case the equilibrium structure of production features disintegration and outsourcing of fragment 1 in industry 3 . Of course, both cases cannot be an equilibrium with the same domestic factor price line $w^{*}$. Theorem 1 is a characterization of equilibrium disintegration for given levels of $\gamma_{i}$ and $\tau_{i}$. The effect of rotating hyperplanes as a result of globalization scenarios will be considered below. Notice also that there is a hyperplane for each industry. For fragmentation to become an issue in a given industry, the individual components of value-added must exhibit different factor intensities. These define a cone which is separated by the hyperplane of Theorem 1. If for this cone has zero measure, then no such separation can arise in that industry.

\section{International disintegration of production}

Assume, in line with the general argument outlined in the introduction, that technological advances and lower trade and communication barriers reduce $\gamma_{i}$, thus causing rotations in the margins of disintegration. In this section, we first look at what determines the size of this shock for an individual industry, and then characterize possible ways to restore conditions of equilibrium with increased disintegration. In the subsequent section we emphasize that such "shocks" are likely to arise simultaneously in several industries, and we look at the factor price effects in a general equilibrium adjustment.

\subsection{Disturbance of the integrated production equilibrium}

To be able to focus on a single fragment, we now stipulate that the cost of disintegration is specific to the fragment involved. To be more concrete, suppose that for the initial costs of disintegration $\gamma_{i 0}^{f}$ a subset $G_{i}$ of fragments is produced domestically, while the complementary set $H_{i}$ is produced abroad. Using a subscript 0 to indicate this initial equilibrium, we have

$$
\begin{aligned}
& w_{0}^{T} \tilde{a}_{i}^{f}\left(w_{0}\right)=\pi_{i 0}^{f} \quad \text { with } \quad s_{i}^{f}\left(w_{0}, w^{*}, \gamma_{i 0}^{f}\right)<0 \quad \text { for } f \in G_{i}, \\
& \text { and } w_{0}^{* T} \tilde{a}_{i}^{f *}\left(w^{*}\right)=\pi_{i 0}^{f} \quad \text { with } \quad s_{i}^{f}\left(w_{0}, w^{*}, \gamma_{i 0}^{f}\right)>0 \quad \text { for } f \in H_{i} \text {, }
\end{aligned}
$$

where $s_{i}^{f}$ is defined in 16 above, and where we now make explicit the role played by the costs of disintegration. Since we assume constant foreign factor prices throughout this analysis, we abstain from indexing $w^{*}$. It should be noted that effective prices in an equilibrium with outsourcing also depend on foreign factor prices, and on the cost 
of disintegration; see Definition 1 above. Thus, $\pi_{i 0}^{f}=\pi_{i}^{f}\left(w_{0}, w^{*}, \gamma_{i 0}\right)$, where $\gamma_{i 0}$ must now be thought of as a vector representation of individual elements $\gamma_{i 0}^{f}$. Notice again the unit convention implying $q_{i 0}^{f}=1 .^{13}$

Suppose, then, that a fall in the costs of locational disintegration of production rotates the margin of disintegration for some industry from a position like $A$ to a position like $B$ in figure $2 .{ }^{14}$ More specifically, assume that the hyperplane defined by theorem 1 crosses the vector $b_{i}^{g}(w)$ for some fragment $g \in G_{i}$ which may thus be secured more cheaply from abroad. In other words, for initial costs of fragmentation $\gamma_{i 0}^{g}$, savings from outsourcing, $s_{i}^{g}$, are negative and a reduction to $\gamma_{i 1}^{g}<\gamma_{i 0}^{g}$ causes $s_{i}^{g}>0$. We shall henceforth call this a "globalization shock". Notice that this need not be the first fragment to be disintegrated from domestic industry $i$ value-added. In any case, we carry out a "marginal" analysis of globalization in that we focus on a single fragment (in our case fragment $g$ ) that is affected by this shock.

It is easy to see that this kind of globalization shock implies a violation of the zero profit condition for industry $i$ :

$$
w_{0}^{* T} \gamma_{i} \tilde{a}_{i}^{g *}\left(w_{0}^{*}\right)=\pi_{i 0}^{g}-s_{i}^{g}\left(w_{0}, w_{0}^{*}, \gamma_{i 1}\right) \quad \text { with } \quad s_{i}^{g}\left(w_{0}, w_{0}^{*}, \gamma_{i 1}\right)>0
$$

While condition 19 states that foreign production of fragment $g \in G_{i}$ was a loss-making activity at initial costs of disintegration (and did therefore not take place), equation 21 states that it now generates a positive profit. The unit cost of producing fragment $g$ abroad, including the cost of locational disintegration, is lower than the value imputed to that fragment in the initial equilibrium. Thus, at initial factor prices, the zero-profit condition is violated which generates an incentive for further disintegration of production. For a zero-profit equilibrium to be restored, there has to be some adjustment in factor prices.

Before we turn to the question of what, precisely, this adjustment may look like, we investigate the magnitude of the disturbance as such. Intuitively, it depends on the remaining cost of fragmentation after the globalization shock, on the Ricardian

\footnotetext{
${ }^{13}$ To avoid clutter, I abstain from indexing $g$ although in a general scenario different fragments will be affected in different industries.

${ }^{14}$ In our modeling framework, the exogenous forces determining the margin are $\gamma_{i}$ and $\tau_{i}$. Of course, the margin also changes if there is a change in factor prices, brought about, say, through changing prices of final goods $p_{i}$. However, our purpose here is to explore implications of an increased international disintegration of production on factor prices at constant final goods prices. Hence, we must treat $\gamma_{i}$ and $\tau_{i}$ as exogenous, and factor prices as endogenous variables.
} 
productivity difference between the two economies, and on factor price differences in conjunction with the factor intensity pattern in fragment $g$. This is substantiated in precise terms in the following theorem.

Theorem 2 (cost-savings from fragmentation) Suppose that in some industry $i$ a "globalization-shock" turns $s_{i}^{g}\left(w_{0}, w^{*}, \gamma_{i}^{g}\right)$ from negative to positive, with certain levels of the costs of disintegration and Ricardian technology gaps, $\gamma_{i}$ and $\tau_{i}$, respectively. Suppose that in relative terms the initial factor price difference for factor $m$ is given by $\hat{w}_{m 0}=w_{m}^{*} / w_{m 0}-1$, and represented in vector form by $\hat{w}$. Then, if technology is of the Leontief-type, at initial factor prices there is a disturbance of the zero-profit equilibrium in industry $i$, the magnitude of which - relative to the initial domestic cost of producing fragment $g-i s$

$$
\sigma_{i}^{g}=\left(1-\gamma_{i}^{g} \tau_{i}\right)-\gamma_{i 1}^{g} \tau_{i} \theta_{i}^{g T} \hat{w}_{0}
$$

where $\theta_{i}^{g}$ is a vector representation of the usual factor shares for fragment $g$. For a technology which allows for factor substitution, $\sigma_{i}^{g}$ is increased by a further additive term.

Recognizing equation 21 above, the proof is completed in the appendix. The intuition is quite straightforward. The costs of disintegrating production and the Ricardian technology gaps drive the magnitude of the disturbance in a completely symmetric way. If factors in the foreign economy are less productive, then $\gamma_{i} \tau_{i}>1$, and the first term in $\sigma_{i}^{g}$ is negative. For $\sigma_{i}^{g}$ to be positive, this needs to be offset by a HeckscherOhlin-type advantage arising from the interaction between factor price differences and factor intensities, as represented by the second term in Theorem 2 .

\subsection{Possible adjustments}

If the cost of disintegrating production falls such that further international fragmentation becomes attractive, then some factor prices must increase, reflecting the benefit of an improved technology. In general, such an increase may take place abroad or at home, or in both economies. A full treatment of this question would require a model where foreign factor prices are endogenous. Here we look at the case where foreign factor prices are given and constant. But even in this simpler case, much can happen. In particular, domestic factors may gain quite disproportionately. Indeed, it cannot be ruled out that some factors suffer a real income loss.

It should be noticed that simple reference to the Stolper-Samuelson theorem does not suffice to establish this case since lower $\gamma$ 's imply some form of lower cost at 
unchanged commodity prices. In contrast, the Stolper-Samuelson theorem is based on goods price changes at unchanged technology. More importantly, if lower $\gamma$ 's lead to outsourcing, then there is a potentially dramatic change in the technology used to generate domestic value-added which, in turn, seems to preclude a direct application of the Stolper-Samuelson theorem to the problem of outsourcing. However, the notion of effective prices for fragments allows us to frame outsourcing scenarios in such a way that one can still draw on the fundamental logic of the Stolper-Samuelson theorem in order to identify their factor price effects.

Specifically, the factor price adjustments following an "outsourcing disturbance" of the type described above can be analyzed by asking how it changes effective fragment prices, and by mapping these fragment price changes into factor price changes. The principal complication is that we are looking at fragments of a value-added chain, rather than well-defined goods. The Stolper-Samuelson theorem relies on the assumption that each good is produced with a well-defined pattern of factor inputs which follows from cost-minimization and depends only on factor prices. The following definition captures this basic notion, such that the subsequent analysis can be framed in terms of the familiar Stolper-Samuelson logic.

Definition 2 (Stolper-Samuelson-type disturbance) A Stolper-Samuelson disturbance is defined as any change in the economic environment which alters the market value of a single activity with a well-defined and unique pattern of primary factor inputs per unit of this activity, whereby these inputs depend only on prevailing factor prices.

From 19 and 20 plus the underlying definitions of effective prices and the zero-profit condition, the initial equilibrium must satisfy

$$
\sum_{f=1}^{F} \pi_{i 0}^{f}=1 .
$$

It may appear puzzling that the sum of effective fragment prices should always add up to one in the initial equilibrium. One expects, for instance, that a lower final goods price $p_{i}$, or a lower productivity level, should be reflected in a lower level of effective prices, while 22 states that effective prices always lie on a "unit-plane". The puzzle is easily resolved by observing the unit convention behind effective prices in definition 1 above. Specifically, lower effective prices for given "natural" units of fragments show up as a change in units considered, with the effective price $\pi_{i}^{f}$ now relating to a larger quantity of fragment $f$. With constant foreign factor prices, we may rewrite 22 as

$$
\sum_{f \in G_{i}} \pi_{i 0}^{f}=1-\sum_{f \in H_{i}} \gamma_{i 0}^{f} w^{* T} \tilde{a}_{i}^{f *}\left(w^{*}\right)
$$


noting again that $q_{i 0}^{f}=1$. For easier notation, we write $\tilde{H}=\sum_{f \in H_{i}} \gamma_{i 0}^{f} w^{* T} \tilde{a}_{i}^{f *}\left(w^{*}\right)$ for the total factor cost of obtaining "foreign fragments" as required per unit-value of the final good in the initial equilibrium, inclusive of the costs of disintegration.

To proceed with the analysis, we introduce a further definition of prices relating to fragments. Thus, for those fragments initially produced at home $\left(f \in G_{i}\right)$, we define $\bar{\pi}_{i}^{f}$ as the input prices "mandated" by $\tilde{H}$, irrespective of whether they satisfy the zero-profit condition 19 for domestic production. These prices must satisfy

$$
\sum_{f \in G_{i}} \bar{\pi}_{i}^{f}=1-\tilde{H}
$$

One can interpret alternative points on the plane 24 as hypothetical prices for fragments (as opposed to factor inputs) which would allow firms to secure the initial levels of fragment inputs $q_{i 0}^{f}=1$ (for $f \in G_{i}$ ) at the same total cost. In the initial equilibrium, this cost is equal to what is left from a dollar's worth of revenue, after paying the cost of fragments already outsourced to the foreign economy.

Figure 3 looks at the case where, prior to the globalization scenario, the number of fragments in $G_{i}$ has already been cut down to 2 , say fragments 1 and 2 , with $g=2$. The initial equilibrium $\left\{\pi_{i 0}^{1}, \pi_{i 0}^{2}\right\}$ must obviously lie on the straight line 24 . Other points on this line would facilitate the same input cost if fragments did, indeed become available at the respective prices. However, if all fragments in $G_{i}$ are to be produced domestically, then other points on this line would, in general, require domestic factor prices different from $w_{0} \cdot{ }^{15}$ This is necessarily true if the number of factors is equal to, or larger than the number of fragments in $G_{i}$, and if fragments have different factor intensities. In this case, the equilibrium factor price vector $w_{0}$ uniquely determines the effective prices consistent with zero profits in domestic production of fragments $f \in G_{i}$. If the number of factors is smaller than the number of fragments in $G_{i}$, then equilibrium factor prices $w_{0}$ would allow for some degree of freedom as regards effective prices of fragments in $G_{i}$, but except for a coincidence the set of effective prices consistent with $w_{0}$ would not lie on the line $24 .^{16}$

\footnotetext{
${ }^{15}$ Notice the difference between prices $\bar{\pi}_{i}^{f}$ and effective prices according to definition 1 above. 24 only looks at the "upper level" technology of assembling fragments to final goods, whereas definition 1 is also concerned with the production of fragments on the "lower level" of technology.

${ }^{16}$ To see this, take the simplest case with only one factor and two fragments. If the input-coefficients for the two fragments are different, then the fragment price-line consistent with zero profits has a slope different from one and, thus, does not coincide with the straight line 24 .
} 
To proceed with the analysis, I now assume that technology features functional separability in the sense that the two components 1 and 2 can be aggregated to a composite input $G$ according to a concave aggregator $q_{i}^{G}\left(q_{i}^{1}, q_{i}^{2}\right) .{ }^{17}$ This implies that there is a dual cost function $c_{i}^{G}\left(\bar{\pi}_{i}^{1}, \bar{\pi}_{i}^{2}, q_{i}^{G}\right)$ which is concave in prices $\bar{\pi}$. Given all fragments are scaled such that $q_{i 0}^{f}=1$, the initial level of this composite input is equal to $q_{i}^{G}(1,1)$. The initial equilibrium point $\left\{\pi_{i 0}^{1}, \pi_{i 0}^{2}\right\}$ must lie on the "fragment price price frontier" defined by

$$
c_{i}^{G}\left[\bar{\pi}_{i}^{1}, \bar{\pi}_{i}^{2}, q_{i}^{G}(1,1)\right]=1-\tilde{H}
$$

Suppose now that fragments do become available at prices different from their initial equilibrium levels $\left\{\pi_{i 0}^{1}, \pi_{i 0}^{2}\right\}$. After all, this is what outsourcing is all about. Disregarding the implications for domestic factor prices for a moment, other input prices for fragments imply that $q_{i}^{1}=1$ and $q_{i}^{2}=1$ is no longer optimal if technology allows for substitution among fragments. Conversely, if $q_{i 0}^{1}=1=q_{i 0}^{2}$ is optimal, then the fragment price frontier 25 must be tangent to the line 24 at the equilibrium point $\left\{\pi_{i 0}^{1}, \pi_{i 0}^{2}\right\}$, implying that Shephard's lemma indeed leads to $q_{i 0}^{1}=1=q_{i 0}^{2}$.

If fragment 2 is now outsourced, with a savings effect as described by theorem 2 above, then the input price for this fragment is reduced by $\sigma_{i}^{2}$ in proportional terms, and by $\sigma_{i}^{2} \times \pi_{i 0}^{2}$ in absolute terms. If foreign factor prices remain constant, and if the aggregator $q_{i}^{G}\left(q_{i}^{1}, q_{i}^{2}\right)$ is of the Leontief-type, then the fragment price frontier 25 coincides with the line 24 , and the ensuing adjustment must entail a relative change in the effective price of fragment 1 equal to $\sigma_{i}^{2} \times \pi_{i 0}^{2} / \pi_{i 0}^{1}$. If technology allows for substitution between fragments 1 and 2 , then the fragment price frontier is strictly convex, and the "mandated" increase of the effective price of fragment 1 exceeds $\sigma_{i}^{2} \times \pi_{i 0}^{2}$, moving to point $P_{1}$ on the fragment price frontier in figure 3 . Of course, this does not complete the adjustment story, even from a partial equilibrium point of view. First, in figure 3 we realize from the steeper slope of the fragment price frontier at $P_{1}$ that adjustment involves a substitution away from fragment 1 towards fragment 2 . Secondly, and more importantly, the higher effective price of fragment 1 implied by this adjustment must also be supported by factor prices different from $w_{0}$. In other words, a higher "mandated" effective price for domestic fragment 1 in turn "mandates" higher domestic factor prices.

In the simple case of figure 3 , the vertical distance between points $P_{0}$ and $P_{1}$ is a

\footnotetext{
${ }^{17}$ On this form of separability, see Varian (1992, pp. 150-152).
} 
measure of the overall domestic factor price increase that is "mandated" by the lower cost of locational disintegration and the attendant outsourcing of fragment 2. We shall henceforth call this the "industry gain from outsourcing", and we use $\sigma_{i}^{1}$ to indicate this gain relative to the initial effective price of fragment 1 (which remains domestic). As far as industry $i$ alone is concerned the precise distribution of this overall gain across different factor owners is indeterminate, unless there is only one factor. A proportional increase in all factor rewards equal to the industry gain is a possible, but not the only outcome. The distributional effect of outsourcing can only be determined by general equilibrium considerations to which we shall turn in the next section.

It is important for what follows that the industry gain $\sigma_{i}^{1}$ is a Stolper-Samuelson disturbance, since $\pi_{i 0}^{1}\left(1+\sigma_{i}^{1}\right)$ must be seen as the post-outsourcing market value of fragment 1 which is, by definition, characterized by a well defined pattern of primary factor inputs in the sense of definition 2. It is relatively easy to generalize this result to the case where more than one component of the value-added chain remain in the domestic economy. What we need is an extension of the above separability assumption. Thus, if functional separability gives rise to an effective fragment price frontier for all fragments in $G_{i}$, and if the fragments remaining in the post-outsourcing domestic value-added chain are in the same sense separable from component $g$ which is outsourced, then the generalization is straightforward. We shall henceforth call this composite activity residual value-added and indicate it with $\bar{G} \cdot{ }^{18}$ A perfectly analogous generalization is possible with Hicksian aggregation instead of functional separability. This case arises if all fragments of the post-outsourcing domestic value-added chain have constant relative effective prices. ${ }^{19}$ The different fragments of domestic value-added will then be used in constant proportions which, in turn, implies that the value-added process as a whole is characterized by a unique pattern of primary factor inputs depending on factor prices. The above line of argument thus leads to the following theorem.

Theorem 3 (Stolper-Samuelson disturbance) $A$ "globalization shock" of the kind underlying Theorem 2 generates a Stolper-Samuelson disturbance for the domestic industry $i$,

1. if foreign factor prices $w^{*}$ are constant,

\footnotetext{
${ }^{18}$ To avoid cluttered notation, I abstain from indexing $\bar{G}$ although this set will be different across industries, as is the specific fragment $g$ affected by outsourcing.

${ }^{19}$ This raises an issue of interpretation which I cannot address here. A possible interpretation is that there are perfect markets for fragments $f \in \bar{G}_{i}$ where industry $i$ firms of negligible importance.
} 
2. if the fragments in $G_{i}$ are functionally separable form those in $H_{i}$, and

3. if the fragments that remain in the domestic value-added chain constitute an integrated economic activity in the sense of functional separability, or by virtue of constant relative effective fragment prices.

In proportional terms, the market value of this residual domestic value-added, indicated by $\bar{G}$, changes by $\sigma_{i}^{\bar{G}} \geq \sigma_{i}^{g} \times \pi_{i 0}^{g} / \pi_{i 0}^{\bar{G}}$, where $\pi_{i 0}^{g}$ and $\pi_{i 0}^{\bar{G}}$, respectively, are initial equilibrium effective prices for activities $g$ and $\bar{G}$ in industry $i$ value-added. In turn, $\sigma_{i}^{\bar{G}}$ is an overall measure of the extent to which the "industry-i-gain" from outsourcing mandates an increase in domestic factor prices.

It is important to note that with a given savings effect related to fragment $g$, the magnitude of the industry-gain $\sigma_{i}^{\bar{G}}$ is driven by the ratio of effective prices $\pi_{i 0}^{g} / \pi_{i 0}^{\bar{G}}$, which is equal to the initial cost of fragment $g$ relative to the total cost of the residual domestic value-added-chain. A relatively small share of residual value-added relative to the fragment which is outsourced thus acts as a leverage for the magnitude of the Stolper-Samuelson disturbance.

\section{General equilibrium: distributional effects}

From a partial equilibrium perspective, the distribution of the industry gain $\sigma_{i}^{\bar{G}}$ across factors is indeterminate. To identify distributional effects of outsourcing, we need to look at the whole economy. Much depends on the number of factors involved and whether they are mobile across sectors or specific to industries. We retain the assumption of an arbitrary number of factors with perfect intersectoral mobility. We allow outsourcing to take place simultaneously in several industries, assuming that in each industry it gives rise to a Stolper-Samuelson disturbance as described in the previous section. The crucial point to bear in mind is that the industry-i-gain from outsourcing reflects an increase in the value of an activity with a well defined factor input pattern which depends on domestic factor prices. This implies, in turn, that factor price changes have a well defined effect on the cost of this activity. If the activity is to remain viable, then factor price changes must be such that the implied increase in this cost is equal to the industry gain $\sigma_{i}^{\bar{G}}$. This must hold for all activities in the economy. However, simply invoking all relevant zero profit conditions is not sufficient to determine factor price changes. We need to broaden our perspective to full general equilibrium, including factor market clearing conditions. 


\subsection{Some factors may suffer a real income loss}

The general line of reasoning is best understood by looking at figure 4 which refers to figures 1 and 2 above in assuming that the initial equilibrium features domestic specialization on industries 2 and 3, with no international disintegration of production. We now assume that this equilibrium is disturbed by lower costs of international fragmentation. For simplicity, we first look at the case where outsourcing is restricted to industry 2 . The more general case will be dealt with below. The unit-value isoquants for final goods 2 and 3 are tangent to the initial factor price line $w_{0}$. So are the industry-2-isoquants corresponding to the unit-value levels of fragment 1 and the composite activity $\bar{G}_{2}$, respectively (dashed lines), given their initial effective prices $\pi_{20}^{1}$ and $\pi_{20}^{\bar{G}}$, The assumption thus is that a shift in the margin of disintegration will lead to outsourcing of fragment 1 in industry 2 .

Referring to the analysis in the previous section, we can now identify the factor price effects from this type of outsourcing by shifting the unit-value isoquant for the residual value-added activity $\bar{G}_{2}$ towards the origin by a proportional distance equal to $\sigma_{2}^{\bar{G}}: \pi_{21}^{\bar{G}}=\pi_{20}^{\bar{G}}\left(1+\sigma_{2}^{\bar{G}}\right)$. The size of $\sigma_{2}^{\bar{G}}$ is determined as described in theorem 2 above. Integrated production of good 2 is no longer viable domestically, nor is fragment 1 of industry 2. Only the remaining part of the value-added-chain (activity $\bar{G}$ ) remains viable. Capital suffers an income loss, while labor gains. If final goods prices remain constant as assumed, then these are also real income changes. This corresponds to the case considered by Arndt $(1997,1999)$.

It is fairly obvious, however, that this case does not establish a general result. Assume, for instance that the residual factor intensity ray $b_{2}^{\bar{G}}$ lies to the south-east of $a_{3}$ (not depicted, to avoid clutter). In that case international fragmentation, while still affecting the labor intensive of the two industries, increases the imputed value of an activity which is relatively capital intensive, and the same logic leads to a real income loss (gain) for labor (capital). But this is consistent with a full employment equilibrium only if the domestic endowment ray similarly lies to the south-east of $a_{3}$, such as $V^{\prime}$ instead of $V$. Indeed, it can be shown using figure 4 that the two cases are mutually exclusive, and factor endowments determine which case is ruled out. A full analysis thus requires looking at domestic factor endowments and factor market clearing. A first result is easily derived from figure 4 .

Theorem 4 (real income loss) If outsourcing is driven by factor intensity differences across fragments (as described by Theorem 2), and if it takes place only in industry $i$, then, with given domestic endowments and perfect flexibility of factor prices, 
some factors will necessarily suffer a real income loss, unless the residual factor intensity $b_{i 0}^{\bar{G}}$ satisfies $b_{i 0}^{\bar{G}}=e V$, where $e$ is a positive scalar and $V$ is the domestic endowment vector. If $b_{i 0}^{\bar{G}}=e V$, then all activities except $b_{i 0}^{\bar{G}}$ become nonviable economically, and all factor prices rise by the same proportional amount $\sigma_{i}^{\bar{G}}$.

The proof is straightforward. Full employment of factor endowments requires that $V$ lies in a cone spanned by the factor-input rays of all viable activities. In figure 4 , the relevant cone prior to outsourcing is spanned by $a_{20}$ and $a_{30}$, and with international fragmentation it is spanned by $b_{21}^{\bar{G}}$ and $a_{31}$, respectively. If $b_{i 0}^{\bar{G}} \neq \mathrm{eV}$, then full employment requires that some other activity remains viable, in addition to the residual value-added-chain of industry 2. Given constant final goods prices, this in turn requires constant unit-cost for some other activity which, by construction of our argument, does not itself benefit from outsourcing. Thus, the familiar Stolper-Samuelson logic applies: the industry-i-gain $\sigma_{i}^{\bar{G}}$ requires that some factor prices increase (labor in figure 4), while the viability constraint on some other activity requires that at least one factor price declines (capital rental in figure 4).$^{20}$ With constant final goods prices, these are also real income changes.

\subsection{A general result on distributional consequences}

Theorem 4 is obviously an extreme case with rather limited empirical relevance. However, it is a useful step towards a more general result on distributional consequences of outsourcing. Thus, let us assume that international fragmentation affects several industries at the same time. The industry-specific features of the shock are summarized by certain magnitudes of the industry-gains $\sigma_{i}^{\bar{G}}$, and by the technology pertaining to the residual value-added-chains. These technologies are captured by the factor input bundles $a_{i}^{\bar{G}}(w)$ or, equivalently, by the unit-value levels of these bundles which are defined as in 11. Remember that we have employed a simple scaling assumption such that the initial equilibrium is characterized by unit-levels for all fragments, $q_{i 0}^{f}=1$. Hence, $a_{i}^{\bar{G}}\left(w_{0}\right)=\sum_{f \in \bar{G}_{i}} \tilde{a}_{i}^{f}\left(w_{0}\right)$ where a tilde indicates inputs per unit of a fragment. Invoking the separability assumption underlying theorem 3 above, we now use $\tilde{a}_{i}^{\bar{G}}(w)$ to denote the cost-minimizing input bundle per unit of the aggregate residual activity

\footnotetext{
${ }^{20}$ In figure 4 , a case where $b_{i 0}^{\bar{G}}=e V$ cannot arise because final good 3 is the only activity remaining besides $b_{i 0}^{\bar{G}}$. But in the more general case where several further activities are present, such a case is easily conceivable.
} 
$\bar{G}$. Without loss of generality, we may scale units such that $\tilde{a}_{i}^{\bar{G}}(w)=a_{i}^{\bar{G}}\left(w_{0}\right)$.

We now introduce factor market clearing by means of the dual GNP function. ${ }^{21}$ Due to international fragmentation, however, this function appears in a slightly complicated form:

$$
y\left(p, V, w^{*}, \gamma_{i}\right)=\min _{w}\left\{w^{T} V \mid c_{i}(w) / p_{i} \geq 1 \quad \text { for all } i\right\} .
$$

Allowing for international disintegration of production, the minimum cost functions in 26 need to be replaced by appropriate expressions pertaining to individual fragments (see 2 above), duly taking into account foreign factor prices $w^{*}$, which in this case become a further determinant of domestic GNP, as do the costs of international fragmentation $\gamma_{i}$. Thus, in the initial equilibrium factor prices $w_{0}$ satisfy the inequality constraint postulated by 26 in the specific form of expressions 19 and 20 above, with $\gamma_{i}=\gamma_{i 0}$. These conditions state that the minimum cost of each fragment, wherever it is produced, is equal to its imputed market value, with the inequalities ruling out further cost reductions by relocating production of individual fragments. At this stage it becomes relevant whether the real resources used through the cost of international fragmentation are domestic or foreign resources. The way we model these costs implies that they involve foreign, not domestic, factor use. This is not a crucial element for the result to be derived below.

We now turn to a scenario of further disintegration of production, brought about by lower costs of disintegrating production, $\gamma_{i 1} \leq \gamma_{i 0}{ }^{22}$ In the above analysis, we have indicated the fragment which will be relocated abroad by $g$. We must now add that in the initial equilibrium a condition analogous to 19 implicitly also holds for the composite residual activity $\bar{G}$ in each industry $i$ which is active in the domestic economy. Denoting the imputed value of that residual activity by $\pi_{i}^{\bar{G}}$, we therefore have

$$
w_{0}^{T} \tilde{a}_{i}^{\bar{G}}\left(w_{0}\right)=\pi_{i 0}^{\bar{G}} .
$$

Lower costs of disintegration now change these market values, leading to StolperSamuelson disturbances in several (in the extreme case: all) industries. Indicating the new equilibrium GNP by $Y_{1}$, we have

$$
Y_{1}=y\left(p, V, w^{*}, \gamma_{i 1}\right)=\min _{w}\left\{w^{T} V \mid w^{T} \tilde{a}_{i}^{\bar{G}}(w) \geq \pi_{i 0}^{\bar{G}}\left(1+\sigma_{i}^{\bar{G}}\right) \text { for all } i\right\} .
$$

\footnotetext{
${ }^{21}$ See Dixit \& Norman (1980, pp. 44 ff.) for a more detailed treatment of the dual GNP function.

${ }^{22}$ Notice that $\gamma_{i}$ is a vector representation of industry-specific costs of international fragmentation.
} 
The new factor prices $w_{1}$ must satisfy this minimization exercise. The question now is how we may describe the difference between $w_{1}$ and $w_{0}$ in a general and interesting way. Remember that the industry gain $\sigma_{i}^{\bar{G}}$ is a summary measure of the factor price increase "mandated" the cost-savings from outsourcing in industry $i$. Suppose now that this gain varies across industries and industry $i^{\prime}$ is the one industry where the gain is at least as large as in all the others. We shall henceforth call industry $i^{\prime}$ the "leading industry".

For benchmark purposes, we define a notional factor price vector

$$
w_{1}^{\prime}=w_{0}\left(1+\sigma_{i^{\prime}}^{\bar{G}}\right) .
$$

Factor prices $w_{1}^{\prime}$ would prevail in the new equilibrium if all industries were to enjoy industry-gains equal to $\sigma_{i^{\prime}}^{\bar{G}}$. Since unit-input-demands are homogeneous of degree zero, and given equation 27 , factor prices $w_{1}^{\prime}$ satisfy the constraint in 28 . Hence, by definition of the GNP function in 28 , we have

$$
\left(w_{1}-w_{1}^{\prime}\right)^{T} V \leq 0
$$

with a strict inequality if industry-gains are different, and if more than one domestic industry survives. This may be rewritten as

$$
\begin{aligned}
\sum_{m=1}^{M}\left[\varphi_{m 1}-\varphi_{m 0} \times \frac{Y_{0}}{Y_{1}}\left(1+\sigma_{i^{\prime}}^{\bar{G}}\right)\right] & \leq 0, \\
\text { or } \quad \frac{Y_{0}}{Y_{1}}\left(1+\sigma_{i^{\prime}}^{\bar{G}}\right) \sum_{m=1}^{M} \varphi_{m 0} & \geq 1,
\end{aligned}
$$

where $\varphi_{m 1}=\left(w_{m 1} V_{m}\right) / Y_{1}$, i.e., the share of factor $m$ in post-outsourcing-GNP, and accordingly for $\varphi_{m 0}$. The second inequality follows from the simple adding-up property of $\varphi_{m 1}$, i.e., $\sum_{m=1}^{M} \varphi_{m 1}=1$. The term $Y_{0}\left(1+\sigma_{i^{\prime}}^{\bar{G}}\right) / Y_{1}$ may be interpreted as a scaling factor representing the benchmark case of equal industry-gains $\sigma_{i^{\prime}}^{\bar{G}}$. Notice that in this special case $Y_{1}=Y_{0}\left(1+\sigma_{i^{\prime}}^{\bar{G}}\right)$, hence 31 holds with equality and income shares do not change. In the more general case, inequality 31 mirrors the fact that an equal percentage increase of all factor remunerations by the maximum industry-gain $\sigma_{i^{\prime}}^{\bar{G}}$ is beyond what outsourcing offers in terms of economy-wide cost-savings.

Definition 3 (distributional impact measure) We define $\Delta \varphi_{m}=\varphi_{m 1}-\varphi_{m 0}\left[Y_{0}(1+\right.$ $\left.\left.\sigma_{i^{\prime}}^{\bar{G}}\right) / Y_{1}\right]$ and $\omega_{m}=\left(w_{m 1}-w_{m 1}^{\prime}\right) / w_{m 0}$ as measures of the distributional impact that outsourcing has on factor $m$. Depending on whether these measures are positive or negative, we may say that factor $m$ gains more than, or less than, proportionally from outsourcing. $\omega$ is a vector representation of $\omega_{m}$. 
Notice that $\Delta \varphi_{m}>0$ if and only if $\omega_{m}>0$, and analogously for $\Delta \varphi_{m}<0$. It is important that we are not characterizing the distributional impact by actual differences between equilibria, because such differences would also reflect the overall gain accruing to the economy from lower costs of fragmentation. Instead, we are taking the hypothetical case of a uniform gain equal to $\sigma_{i^{\prime}}^{\bar{G}}$ as a benchmark to identify distributional consequences.

From our reasoning with figure 4, we expect that the factor price effect of outsourcing is importantly determined by the factor intensity characteristics of outsourcing. We now apply a revealed-cost-minimization argument to the residual activity of the "leading industry" $i^{\prime}$. Remember that $\tilde{a}_{i^{\prime}}^{\bar{G}}(w)$ is an input bundle for the initial quantity-level of the residual value-added-chain which, by suitable scaling, was set equal to one. We now look at the input bundle for a larger quantity $1 / \pi_{i 0}^{\bar{G}}$ which represents a value of one in the sense of definition 11 above. We denote the corresponding input bundle by $\tilde{b}_{i^{\prime}}^{\bar{G}}(w)$.

Definition 4 (factor intensity measure) We define $\theta_{m}=w_{m 0} \tilde{b}_{i^{\prime} m}^{\bar{G}}\left(w_{0}\right)-\varphi_{m 0}$ as a summary measure of the factor-intensity characteristics of outsourcing. $\theta$ is a vector representation of $\theta_{m}$.

This variable measures the extent to which a factor's share in the residual value-addedchain of the "leading outsourcing-industry" exceeds that factors share in initial GNP. Notice that $w_{0}^{T} \tilde{b}_{i^{\prime}}^{\bar{G}}\left(w_{0}\right)=1$; see 27 above. Hence $\sum_{m=1}^{M} \theta_{m}=0$. Notice that we characterize the factor-intensity characteristics not by looking at the fragment which leaves the country, but instead at the residual domestic value-added-chain.

Since industry $i^{\prime}$ satisfies the restriction in 28 with equality, we have

$$
w_{1}^{T} \tilde{b}_{i^{\prime}}^{\bar{G}}\left(w_{1}\right)=1+\sigma_{i^{\prime}}^{\bar{G}} \quad \text { and } \quad w_{1}^{T} \tilde{b}_{i^{\prime}}^{\bar{G}}\left(w_{0}\right) \geq 1+\sigma_{i^{\prime}}^{\bar{G}}
$$

In the new equilibrium, cost-minimizing firms will employ an input bundle $\tilde{b}_{i^{\prime}}^{\bar{G}}\left(w_{1}\right)$ to generate a certain level of the aggregate fragment $\bar{G}$ which was initially imputed a value of one, and which now has an imputed value equal to $1+\sigma_{i^{\prime}}^{\bar{G}}$. Zero profits, therefore, imply that the cost incurred for this level of fragment $\bar{G}$ is also equal to $1+\sigma_{i^{\prime}}^{\bar{G}}$. Under the initial factor prices $w_{0}$, cost-minimizing firms would have used the bundle $\tilde{b}_{i^{\prime}}^{\bar{G}}\left(w_{0}\right)$ to generate this quantity of fragment $\bar{G}$. Doing so under new factor prices would raise costs above $w_{1}^{T} \tilde{b}_{i^{\prime}}^{\bar{G}}\left(w_{1}\right)$ which, by definition is the best firms can do; hence the inequality in the second part of 32 . At the same time, if the cost of $\tilde{b}_{i^{\prime}}^{\bar{G}}\left(w_{0}\right)$ was equal to one at initial factor prices $w_{0}$, as argued above, then using the bundle $\tilde{b}_{i^{\prime}}^{\bar{G}}\left(w_{1}\right)$ would have 
generated a cost in excess of one. We therefore have

$$
w_{0}^{T} \tilde{b}_{i^{\prime}}^{\bar{G}}\left(w_{0}\right)=1 \quad \text { and } \quad w_{0}^{T} \tilde{b}_{i^{\prime}}^{\bar{G}}\left(w_{1}\right) \geq 1 .
$$

Combining the equation in 32 with the inequality in 33 , we have

$$
\left[w_{1} /\left(1+\sigma_{i^{\prime}}^{\bar{G}}\right)-w_{0}\right]^{T} \tilde{b}_{i^{\prime}}^{\bar{G}}\left(w_{0}\right) \geq 0
$$

Multiplying this by $1+\sigma_{i^{\prime}}^{\bar{G}}$ clearly preserves the inequality, such that $\left(w_{1}-w_{1}^{\prime}\right)^{T} \tilde{b}_{i^{\prime}}^{\bar{G}}\left(w_{0}\right) \geq$ 0 . Combining this with inequality 30 , where we may expand each term by $w_{m 0} / w_{m 0}$ and divide by $Y_{0}$, we arrive at Theorem 5 .

Theorem 5 (distributional impact of outsourcing) If globalization leads to simultaneous shifts in the margins of disintegration for several industries, and if there is a "leading industry" $i$ ' where the resulting Stolper-Samuelson disturbance for the residual domestic value-added-chain, $\sigma_{i^{\prime}}^{\bar{G}}$, is at least as large as in any other industry, then the distributional impact of such a shift is related to the factor-intensity characteristics of the resulting process of outsourcing in the following way:

$$
\omega^{T} \theta \geq 0
$$

Given that $\sum_{m=1}^{M} \theta_{m}=0$, as noted above, we may note that the basic result can also be expressed by stating that the correlation coefficient between the two variable $\omega_{m}$ and $\theta_{m}$ across factors is positive.

\subsection{Interpretation}

The general message conveyed by theorem 5 is that the distributional consequences of international fragmentation are not at all determined by the factor-intensity pattern of those fragments which are outsourced to the foreign economy. Instead, they are determined by the factor intensity of the activities that remain economically viable in the domestic economy. Which of the activities remains viable domestically is, in turn, determined by the intersectoral pattern of the Stolper-Samuelson disturbances that arise in the process of outsourcing.

It is, of course, conceivable that activities which were formerly viable at home become unprofitable as factor prices change, even though they are not directly hit by changes in the cost of international fragmentation. Indeed, in the case where we have several industries and only two primary factors, such "extreme specialization effects" are almost inevitable. This is a well-known property of Heckscher-Ohlin models which 
- unsurprisingly - reappears in the present context of international fragmentation. The smaller the discrepancy between the number of final goods (or industries) and primary factors, the less likely are such dimensionality of factor space and final goods space. ${ }^{23}$

It may also be the case that for some industries the margin of disintegration cuts into the domestic value-added-chain not through a fall in the cost international fragmentation, but through the factor price effect stemming from Stolper-Samuelson disturbances in other industries. This case is covered by the above result on the same grounds as the case where whole value-added-chains (rather than individual fragments) become nonviable. The crucial point is that in both cases the inequality constraint in 28 may be used a fortiori for those activities that become nonviable through the factor price change from $w_{0}$ to $w_{1}$. The same does not hold true, however, for activities which were nonviable at initial factor prices and which become viable at $w_{1}$. In theory, this case may even arise in such a way that individual fragments which were formerly produced abroad re-enter the domestic value-added-chain. This process of reverse outsourcing is not covered by the above result.

It should be interesting to see if special cases discussed in the previous literature can be reconstructed from Theorem 5 above under appropriate assumptions. This can be done, for instance, for the seemingly contradictory results emphasized by Arndt (1997 and 1999) and Feenstra \& Hanson (1996 and 1997). Both are special in different ways and can be stated as corollaries of Theorem 5 .

Corollary 1 If there are only two industries and factors (capital $K$ and labor L, say), if outsourcing takes place only in the labor-intensive industry, and if both industries remain viable, then it will be true that $\theta_{L}>0$ and $\theta_{K}<0$, and hence that $\omega_{L}>0$ and $\omega_{K}>0$.

This is the case stressed by Arndt. The inequalities $\theta_{L}>0$ and $\theta_{K}<0$ follow from the above mentioned requirement that the two activities must span a cone containing the endowment point.

Corollary 2 If there is only one industry drawing on many fragments with differing factor-intensities (say skilled labor $S$ relative to unskilled labor $U$ ), and if for some reason it is always the most skill-intensive fragment that is outsourced to the foreign economy, then it will always be true that $\theta_{S}>0$ and $\theta_{U}<0$, and hence that $\omega_{S}>0$ and $\omega_{U}>0$.

\footnotetext{
${ }^{23}$ See Ethier (1984).
} 
This is the case which, by virtue of their model assumptions, emerges in Feenstra \& Hanson. The reason for $\theta_{S}>0$ and $\theta_{U}<0$ is as with the previous corollary.

Corollaries 1 and 2 involve cases which are especially interesting to look at since they use Theorem 5 for a reconstruction of results that have been discussed in previous literature and which seem contradictory at first sight. Other cases for which this could be done are found.in Jones (2000) and Jones \& Kierzkowski (2001b), but available space does not permit any further discussion in this paper.

\section{Conclusion}

Instead of reiterating results, I conclude the paper with a few suggestions for further research. There are obvious and less obvious avenues. The assumption of given world prices for final goods is an obvious candidate for relaxation. The analysis in this paper has looked at outsourcing from a single country perspective, even assuming constant prices in foreign factor markets that outsourcing draws upon. A distinct "flavor of smallness" is thus present in the analysis. If international fragmentation is instead seen as a large scale and world-wide reorganization of vertical production structures, then it is likely to change equilibrium world prices for final goods and thus factor prices in all countries. Scenarios of this kind can only be addressed with the aid of a model where world prices are endogenous.

However, even for cases where world prices of final goods are exogenous and constant, assuming constant foreign factor prices may be unwarranted for specific scenarios of outsourcing. Under the assumption of constant foreign factor prices, outsourcing basically introduces a new productive activity into the foreign economy with an imputed value which is equal to its factor cost at the prices prevailing in foreign factor markets. All cost-savings that arise from a geographical restructuring of production are imputed to higher effective prices of residual domestic value-added-chains. This is a reasonable assumption if domestic firms have some form of ownership advantage, and if the residual domestic value-added is a "downstream" activity which needs to be carried out in the domestic economy, say because of some national advantage, such as a specific form of infrastructure.

In other cases, however, conditions may be such that the fragment which is now produced abroad achieves an imputed value which is equal to its former cost of production at factor prices prevailing in the domestic economy. Then, the activity which newly emerges in the foreign economy has an effective (or imputed) price in excess of its foreign factor cost. In this case, equilibrium adjustment requires some foreign factor 
price change which may be determined along the lines of the above analysis. Further research should specify the precise conditions under which either of these cases is likely to arise.

These conditions most likely also relate to the costs that arise if production is fragmented across national borders. As argued in the introduction, the analysis in this paper has deliberately chosen a somewhat rudimentary treatment of these costs, so as to allow a sharp focus in the channels relevant for factor price changes. A richer model structure would allow for asymmetries between fragments as regards the cost involved if production is disintegrated. In a similar vein, introducing an explicit "upstreamdownstream" dimension into the underlying technology of fragmentation would help to generate sharper results.

A final point relates to the assumption of perfect competition and - related to this - the complete absence of any element of fixed costs. Imperfect competition may be relevant on goods markets and, maybe more interestingly, on labor markets which are often the key concern in connection with outsourcing. ${ }^{24}$ In turn, fixed costs, may be relevant in production proper, or in bridging locational and cultural differences if production takes place under international fragmentation.

It is to be expected that the framework of analysis presented in this paper forms a useful ground for exploring several of these avenues for further research. A key message from this framework is that the consequences of international fragmentation are best understood as arising from changes in effective prices for fragments of the value-addedchain. These vary across industries and the general equilibrium effects of outsourcing depends on where these changes are particularly large, and on the technological details of the marginal fragments affected. The above analysis has opened up ways to pin down the relevant properties in terms of general statements which should prove useful for further research.

\footnotetext{
${ }^{24}$ See, for instance, Skaksen (2001) where outsourcing takes place under a unionized labor market.
} 


\section{Appendix: Proof of Theorem 2}

We first recognize 21, and then decompose the cost-savings achieved by disintegrating fragment $g$ from domestic value-added at notionally unchanged factor prices. From 16 , we have

$$
s_{i}^{g}\left(w_{0}, w^{*}\right)=w_{0}^{T} a_{i}^{g}\left(w_{0}\right)-\gamma_{i 1}^{g} w^{* T} a_{i}^{g *}\left(w^{*}\right) .
$$

This can be decomposed as follows:

$$
\begin{aligned}
s_{i}^{g}\left(w_{0}, w^{*}\right)= & \left(1-\gamma_{i 0}^{g} \tau_{i}\right) w_{0}^{T} a_{i}^{g}\left(w_{0}\right)+\gamma_{i 0}^{g}\left[\tau_{i} w_{0}^{T} a_{i}^{g}\left(w_{0}\right)-w^{* T} a_{i}^{g *}\left(w^{*}\right)\right] \\
= & \left(1-\gamma_{i 0}^{g} \tau_{i}\right) w_{0}^{T} a_{i}^{g}\left(w_{0}\right)+\gamma_{i 0}^{g} \tau_{i}\left(w_{0}-w^{*}\right)^{T} a_{i}^{g}\left(w_{0}\right)+ \\
& \gamma_{i 0}^{g}\left[\tau_{i} w^{* T} a_{i}^{g}\left(w_{0}\right)-w^{* T} a_{i}^{g *}\left(w^{*}\right)\right] .
\end{aligned}
$$

Notice that $s_{i}^{g}>0$ implies that the margin of disintegration in Theorem 1 has crossed $b_{i}^{g}$ such that $\left(w-\gamma_{i 0}^{g} \tau_{i} w^{*}\right)^{T} b_{i}^{g}(w)>0$. Defining $\sigma_{i}^{g}=s_{i}^{g} /\left[w^{T} a_{i}^{g}\left(w_{0}\right)\right]$, we have

$$
\sigma_{i}^{g}=\left(1-\gamma_{i 0}^{g} \tau_{i}\right)-\gamma_{i} \tau_{i} \theta_{i}^{g T} \hat{w}_{0}+\gamma_{i 0}^{g} \frac{w^{* T} a_{i}^{g *}\left(w^{*}\right)}{w_{0}^{T} a_{i}^{g}\left(w_{0}\right)} \theta_{i}^{g * T} \hat{a}_{i}^{g},
$$

where $\theta_{i}^{g}$ and $\theta_{i}^{g *}$ are vector representations of the usual factor shares for fragment $g$. Specifically, for factor $m$ we have $\theta_{i m}^{g}=\left[w_{m 0} a_{i m}^{g}\left(w_{0}\right)\right] /\left[w_{0}^{T} a_{i}^{g}\left(w_{0}\right)\right]$, and analogously for $\theta_{i m}^{g *}$. Moreover, $\hat{w}_{0}$ is a vector of factor price differences between the foreign and domestic economy, expressed in relative terms, such that for factor $m, \hat{w}_{m 0}=w_{m 0}^{*} / w_{m 0}-1$. And the finally, the term $\hat{a}_{i}^{0}$ measures the efficiency-corrected difference in inputs between the two locations of production, with $\hat{a}_{i m}^{g}=\left[\tau_{i} a_{i m}^{g}\left(w_{0}\right)\right] /\left[a_{i m}^{g *}\left(w^{*}\right)\right]-1$. If technology of fragment $g$ is of the Leontief-type, featuring fixed input coefficients for all factors, we have $\hat{a}_{i m}^{g}=0$, which leads to Theorem 2. For a technology allowing for factor substitution, the final term in this equation is always positive by virtue of cost-minimization. 


\section{References}

Arndt, S.W. (1997), 'Globalization and the Open Economy', North American Journal of Economics and Finance 8, 71-79.

Arndt, S.W. (1999), 'Globalization and Economic Development', The Journal of International Trade and Economic Development 8, 309-318.

Arndt S.W. and H. Kierzkowski, eds. (2001), Fragmentation: New Production Patterns in the World Economy, Oxford University Press, Oxford.

Deardorff, A.V. (1979), 'Weak Links in the Chain of Comparative Advantage', Journal of International Economics 9, 197-209.

Deardorff, A.V. (2001a), Fragmentation Across Cones, in: Arndt, S.W. and H. Kierzkowski (eds.), Fragmentation: New Production Patterns in the World Economy, Oxford University Press, Oxford.

Deardorff, A.V. (2001b), 'Fragmentation in Simple Trade Models'. North American Journal of Economics and Finance 12, 121-137.

Dixit A.K. and V. Norman (1980), Theory of International Trade, Cambridge University Press, Cambridge.

Ethier, W.J. (1977), 'The Theory of Effective Protection in General Equilibrium: Effective-Rate Analogues to Nominal Rates', Canadian Journal of Economics 10, 233-245.

Ethier, W.J. (1984), 'Higher Dimensional Issues in Trade Theory' in: R.W. Jones and P.B. Kenen (eds.), Handbook of International Economics, Vol. 1, Elsevier Science B.V., Amsterdam, 131-184.

Feenstra, R.C. (1998), 'Integration of Trade and Disintegration of Production in the Global Economy', Journal of Economic Perspectives 12, 31-50.

Feenstra, R.C. and G.H. Hanson (1996), 'Foreign Investment, Outsourcing and Relative Wages', in: R.C. Feenstra, G.M. Grossman and D.A. Irwin (eds.), Political Economy of Trade Policy: Essays in Honor of Jagdish Bhagwati, MIT Press, Cambridge, Mass., 89-127. 
Feenstra, R.C. and G.H. Hanson (1997), 'Foreign Direct Investment and Relative Wages: Evidence from Mexico's Maquiladoras', Journal of International Economics 42, 371-393.

Feenstra, R.C. and G.H. Hanson (1999), 'The Impact of Outsourcing and HighTechnology Capital on Wages: Estimates for the United States, 1979-1990', Quarterly Journal of Economics 114, 907-940.

Görg, H. (2000), 'Fragmentation and Trade: US Inward Processing Trade in the EU', Weltwirtschaftliches Archiv (Review of World Economics) 136, 403-422.

Grossman, G.M. and E. Helpman (2002a), 'Integration versus Outsourcing in Industry Equilibrium', Quarterly Journal of Economics 117, 85-120.

Grossman, G.M. and E. Helpman (2002b), Outsourcing in a Global Economy, National Bureau of Economic Research Working Paper 8728, Cambridge, Mass.

Harris, R.G. (1995), 'Trade and Communication Costs' Canadian Journal of Economics 28, 46-75.

Harris, R.G. (2001), 'A Communications Based Model of Global Production Fragmentation', in: Arndt, S.W. and H. Kierzkowski (eds.), Fragmentation: New Production Patterns in the World Economy, Oxford University Press, Oxford.

Hummels, D., D. Rapoport, J. Ishii and .K. Yi (1998), 'Vertical Specialization and the Changing Nature of World Trade', Federal Reserve Band of New York Economic Policy Review June 1988, 79-99.

Hummels, D., J. Ishii and K. Yi (2001), 'The Nature and Growth of Vertical Specialization in World Trade', Journal of International Economics 54, 75-96.

Irwin, D.A. (1996), 'The United States in a New Global Economy? A Century's Perspective', American Economic Review, Papers and Proceedings 86, 41-46.

Jones, R.W. (2000), Globalization and the Theory of Input Trade, MIT Press, Cambridge, Mass.

Jones, R.W. and H. Kierzkowski (1990), 'The Role of Services in Production and International Trade: A Theoretical Framework', in: R.W. Jones and A.O. Krueger (eds.), The Political Economy of International Trade, Basil Blackwell, Oxford, $31-48$. 
Jones, R.W. and H. Kierzkowski (2001a), 'A Framework for Fragmentation', in: Arndt, S.W. and H. Kierzkowski (eds.), Fragmentation: New Production Patterns in the World Economy, Oxford University Press, Oxford.

Jones, R.W. and H. Kierzkowski (2001b), 'Globalization and the Consequences of International Fragmentation', in: Dornbusch, R. G. Calvo and M. Obstfeld (eds.), Money, Capital Mobility, and Trade, Essays in Honor of Robert A. Mundell, MIT Press, Cambridge, Mass.

Kohler, W. (2001), 'A Specific Factors View on Outsourcing', North American Journal of Economics and Finance 12, 31-53.

Krugman, P. (1995), 'Growing World Trade: Causes and Consequences', Brookings Papers on Economic Activity 1:1995, 327-377.

Leamer, E.E. (1998), 'In Search of Stolper-Samuelson Linkages Between International Trade and Lower Wages', in: Collins, S.M (ed.), Imports, Exports, and the American Worker, Brookings Institution Press, Washington, D.C., 141-203.

Markusen, J.M. (2001), 'Integrating Multinational Firms into International Economics', NBER Reporter, Winter 2001/2002, 5-7.

Markusen, J.M. (2002), Multinational Firms and the Theory of International Trade, MIT Press, Cambridge, Mass.

McLaren, J. (2000), 'Globalization and Vertical Structure', American Economic Review $90,1239-1254$.

Samuelson, P.A. (2001), 'A Ricardo-Sraffa Paradigm Comparing Gains from Trade in Inputs and Finished Goods', Journal of Economic Literature 39, 1204-1214.

Skaksen, J.R. (2001), Who Gain and Who Lose on International Outsourcing, Working Paper, Department of Economics, University of Southern Denmark, Odense.

Varian, H.R. (1992), Microeconomic Analysis, 3rd ed., W.W. Norton, New York.

Venables, A.KJ. (1999), 'Fragmentation and Multinational Production', European Economic Review 43, 935-945. 


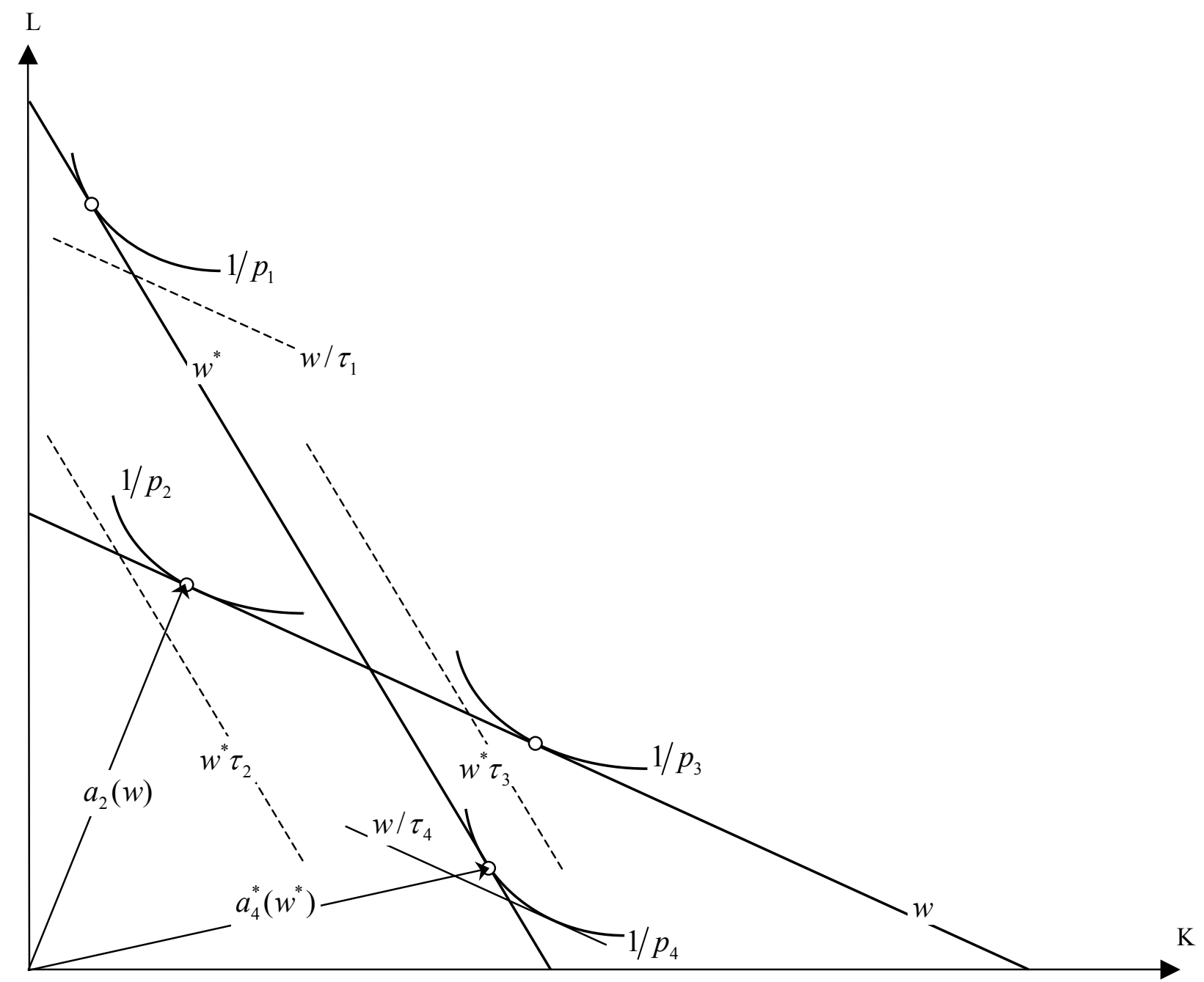

Figure 1: Pre-fragmentation trading equilibrium 


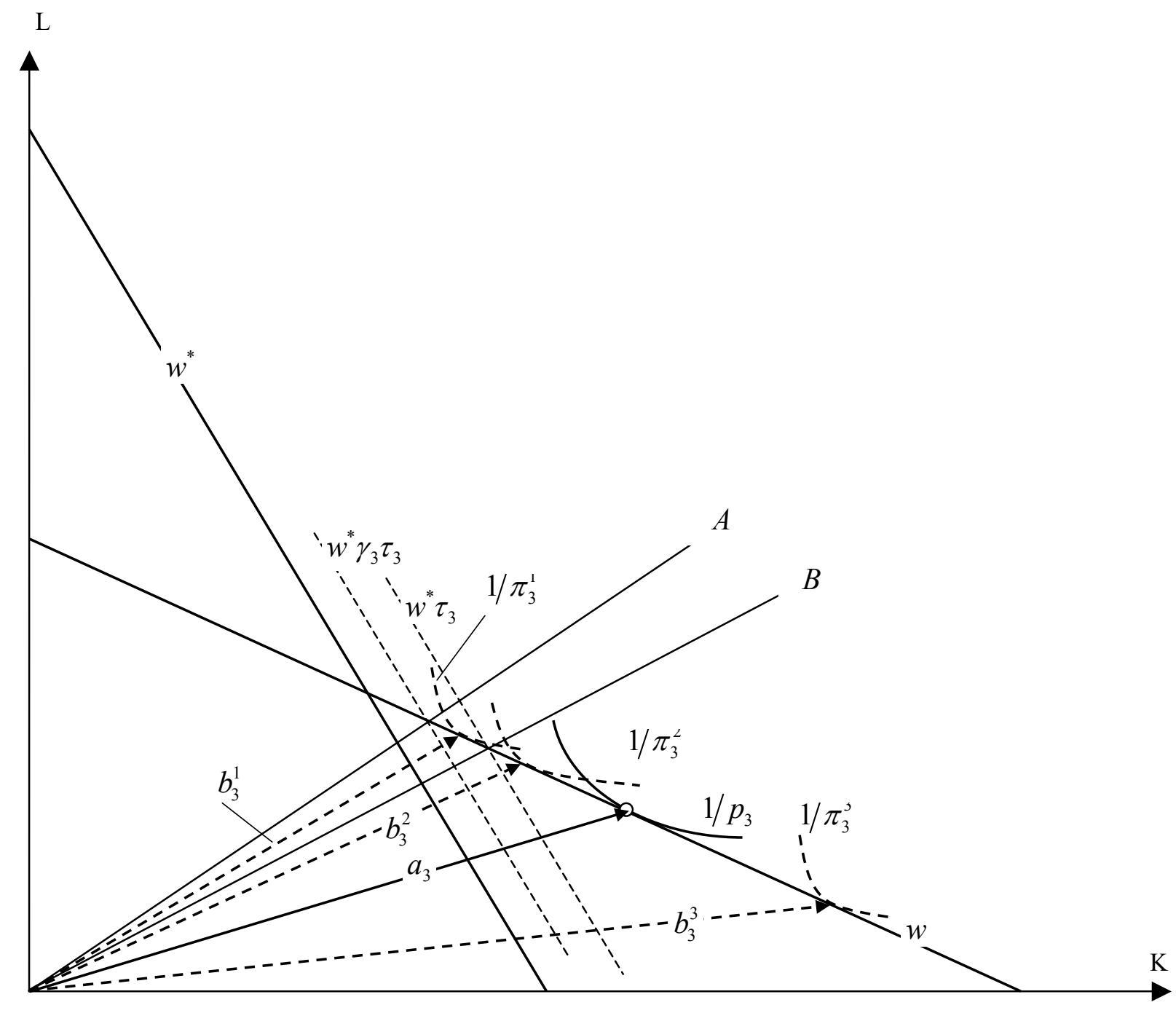

Figure 2: Equilibrium under fragmentation 


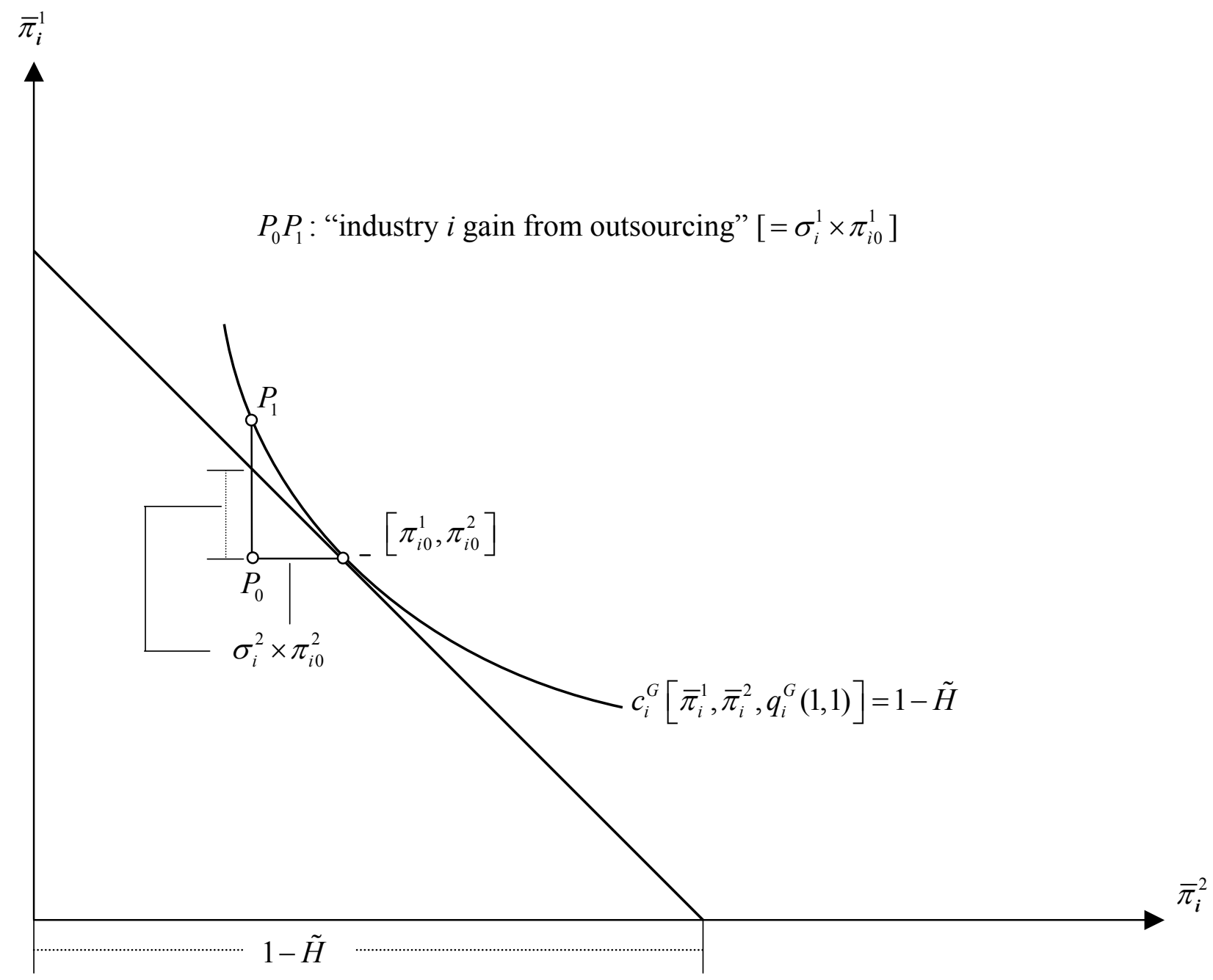

Figure 3: Industry gain from outsourcing 


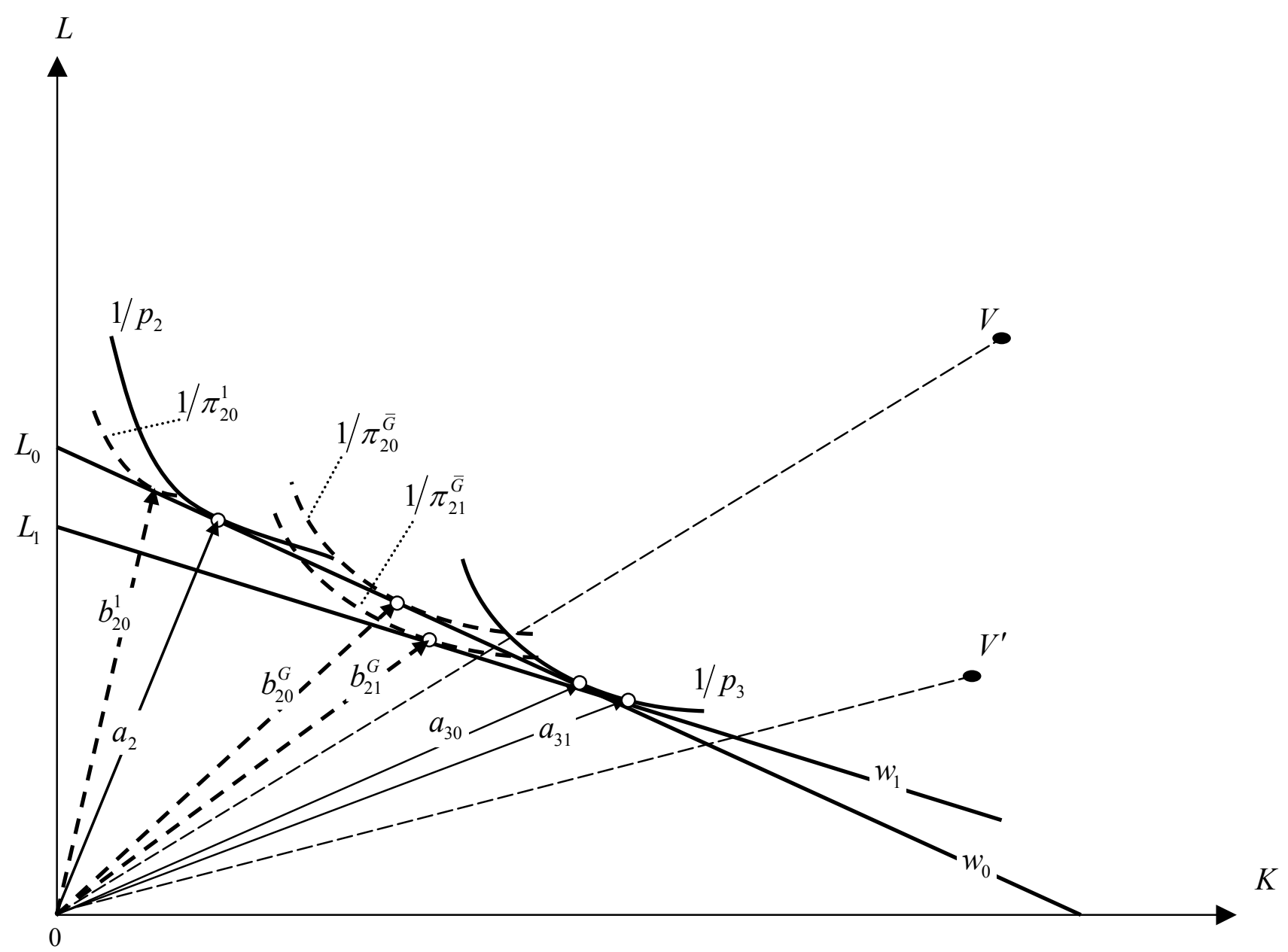

Figure 4: General equilibrium effect of outsourcing on domestic factor prices 